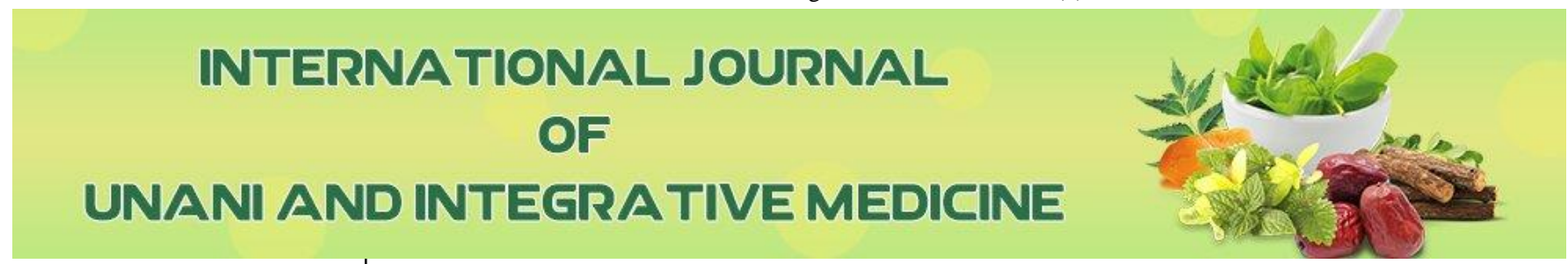

E-ISSN: $2616-4558$

P-ISSN: 2616-454X

IJUIM 2020; 4(3): 27-30

Impact Factor (RJIF): 6.3

Peer Reviewed Journal

Received: 23-06-2020

Accepted: 26-08-2020

\section{Adnan Mastan}

Department of Unani, All India Institute of Medical

Sciences, Raipur,

Chhattisgarh, India
Corresponding Author:

Adnan Mastan

Department of Unani, All

India Institute of Medical

Sciences, Raipur,

Chhattisgarh, India

Email ID:

dradnanmastan@aiimsraipur.e du.in

\section{Incredible health benefits of Adusa (Adhatoda vasica)}

\section{Adnan Mastan}

DOI: $\underline{\text { https://doi.org/10.33545/2616454X.2020.v4.i3a.141 }}$

\begin{abstract}
Adusa is a well-known herbal remedy used in Unani system of medicine for its beneficial effects, especially in bronchitis. The herb containing fresh, dried, ripe leaves of Adhatoda vasica Nees, Family Acanthaceae, is a sub-herbaceous bush which grows and found throughout the year in plains and subHimalayan tracts in India, ascending up to $1200 \mathrm{~m}$., flowering occurs during February-March and also at the end of rainy season. Adusa leaves, bark, root bark, fruit and flowers help to remove intestinal parasites. Adusa herb is used in the treatment of cold, cough, bronchitis and asthma. In acute bronchitis especially when the sputum is thick and sticky, it gives unfailing relief. Its action on liquefying the sputum makes it easier for body to expel sputum. It's dried leaves may be smoked to get relief from asthma. Local application of poultice of adusa leaves is also used with beneficial results over rheumatic joints, inflammatory swellings and fresh wounds. Scabies and other skin diseases may also be treated with a warm decoction of its leaves. In this paper general medicinal uses and pharmacological activities of various parts of this plant have been discussed and reviewed.
\end{abstract}

Keywords: Adusa, Adhatoda vasica, Unani medicine, traditional uses, health benefits

\section{Introduction}

Adhatoda vasica Nees (family Acanthaceae), commonly known as adusa or vasaka, also called malabar nut tree. It is a popular herb of Unani system of medicine due to its beneficial effects, especially in respiratory disorders. It is an evergreen shrub found in many regions of India and around the world. Adusa leaves have a stimulating effect on the respiratory system. Adusa possesses antispasmodic and expectorant properties, and has been used with great success in treating asthma, chronic bronchitis, and other respiratory conditions for centuries. It's boiled leaves may be helpful in treating rheumatic pain, and to relieve the pain of urinary tract infections. Its abortifacient properties have also been established. In some parts of India, it is also used to stimulate uterine contractions, thereby speeding up delivery ${ }^{[1]}$.

\section{Vernacular names ${ }^{[2]}$}

Urdu: Adusa, Basa

Persian: Bansa

Assamese: Titabahak, Bahak, Vachaka

Bengali: Baksa, Vasaka

English: Vasaka

Gujarati: Aduso, Ardusi, Adulso

Hindi: Aduss, Arusa

Kannada: Adsale, Adusoge, Atarusha, Adsole, Adasale

Kashmiri: Vasa

Malayalam: Attalatakam, Atalotakam

Marathi: Vasa, Adulsa

Oriya: Basanga

Punjabi: Bhekar, Vansa, Arusa

Sanskri: Vasaka

Tamil: Vasambu, Adathodai

Telugu: Addasaramu

\section{Plant description}

Family of Adhatoda vasica Nees is Acanthaceae. It occurs throughout the year and known as timeless shrub measuring 1-3 feet in height with many long opposite branches. The leaves are large and lance-shaped. Stem is herbaceous above and woody below. 
Leaves are opposite and estipulate. Flowers have spikes or panicles and are small irregular zygomorphic, bisexual and hypogynous ${ }^{[3]}$. It has capsular four seeded fruits. Color of the flower is either white or purple. Inflorescences in auxiliary spicate cymes, densely flowered; peduncles short; bracts broadly ovate, fallacious. Leaves, flowers, fruits and roots of the plants are extensively used for treating chronic bronchitis, cold \& cough, whooping cough, asthma and also used as sedative, antispasmodic and expectorant ${ }^{[4]}$.

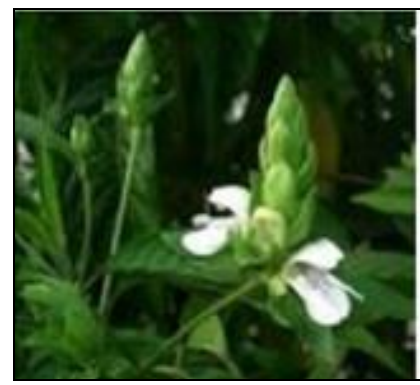

Fig 1: Whole Plant

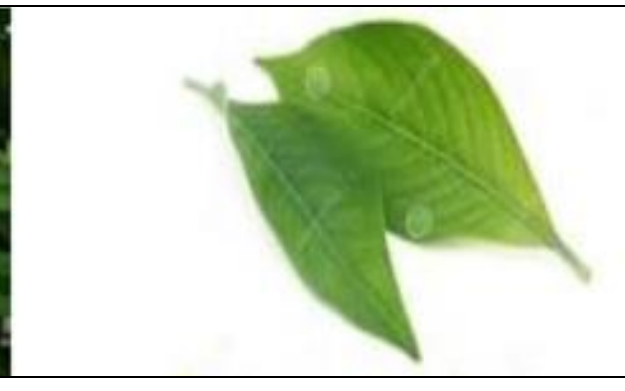

Fig 2: Fresh leaves

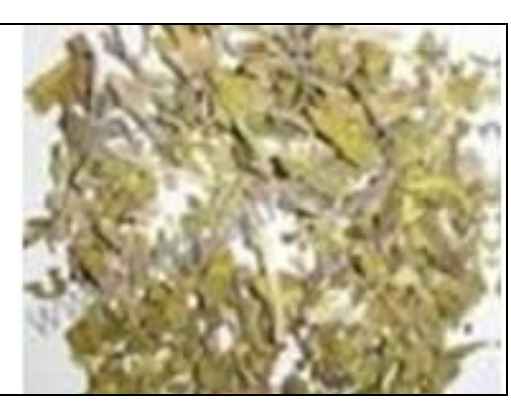

Fig 3: Dried leaves

\section{Temperament \\ Mizaj: $\operatorname{Hot}^{2}$ Dry $^{2}[5]$.}

Parts Used: Leaf and flower ${ }^{[5]}$.

\section{Chemical constituents}

The incredible health benefits and treasure trove pharmacological uses of adusa are because of its rich concentration of alkaloids ${ }^{[6,7]}$. The main alkaloid found in adusa leaves is a quinazoline alkaloid known as vasicine ${ }^{[8]}$. Additionally to vasicine, alkaloids like 1-vasicinone, deoxyvasicine, maiontone, vasicinolone and vasicinolare also present in the leaves and roots of adusa ${ }^{[7]}$. Research suggests that these chemicals are responsible for bronchodilatory effect of adusa ${ }^{[9,10]}$. There has also been a report of thrombopoietic (platelet increasing) activity with vasicine ${ }^{[11]}$. The leaves of adusa are rich in vitamin $\mathrm{C}$ and carotene.

Identity, purity and strength ${ }^{[2]}$.

Foreign matter: Not more than 2 percent

Total ash: Not more than 21 percent

Acid-insoluble ash: Not more than 1 percent

Alcohol-soluble extractive: Not less than 3 percent

Water-soluble extractive: Not less than 22 percent

\section{TLC}

T.L.C of the pet. using pet. ether: ethyl acetate (24:1) extract on silica gel ' $G$ ' plate shows five major spots on spraying with $5 \%$ methanolic-sulphuric acid reagent and heating plate for about ten minutes at $110{ }^{\circ} \mathrm{C}$ at Rf. $0.94,0.42,0.32,0.24$ and $0.13^{[2]}$.

\section{Therapeutic uses and health benefits}

Anti-asthmatic and bronchodilator activity: In Unani system of medicine adusa has been used mainly to treat respiratory disorders. Vasicine and vasicinone are well established as therapeutical respiratory agents; both of them are the primary alkaloid constituents of adusa ${ }^{[11]}$. Extracts of adusa's leaves and roots are used in the treatment of bronchitis, and other lung and bronchiole disorders, as well as common cough \& cold. It's leaves decoction gives soothing effect on irritation in throat, and also act as an expectorant by liquefying phlegm in the respiratory passages. In order to explore the antitussive properties, experimental studies were conducted on anesthetized guinea pigs and rabbits using extract of adusa which showed that plant possesses good antitussive activity ${ }^{[12]}$. Both in vitro and in vivo bronchodilatory activity using vasicine have been established in recent investigations ${ }^{[13]}$.

Wound healing activity: For the purpose of the study, wounds were created along the vertebral column of buffalo calves, then alcoholic and chloroform extracts of adusa in a powdered form were applied. In comparison to control group, the calves treated with adusa showed significant improvement in healing. Role of adusa in wound repair tissue was studied; showed improved breaking strength, tensile strength, absorption and extensibility. In addition to this, animals treated with adusa showed increased levels of elastin, collagen, hydroxyproline, hexosamine and zinc ${ }^{[14]}$.

Anti-ulcer activity: Adhatoda vasica has also been studied for its anti-ulcerogenic activity against ulcers induced by ethanol, pylorus, and aspirin. In a controlled study; powder of dried leaves of adusa showed substantial anti-ulcer activity in experimental rats. The highest degree of activity was observed in the ethanol-induced ulceration model ${ }^{[6]}$. These results suggest that Adhatoda vasica has immense potential as an anti-ulcer agent in addition to its traditionally established pharmacological activities. Further research showed that syrup of adusa improved symptoms of dyspepsia ${ }^{[15]}$.

Cholagogue activity: In laboratory experiments when animals were given an intravenous dose of $5 \mathrm{mg} / \mathrm{kg}$, Adhatoda vasica was found to increase bile activity. Study on dogs showed that the amount of bile excretion was increased by $40-100 \%$. The animals also showed an increase in bilirubin excretion ${ }^{[16]}$.

Anti-allergy activity: An extract composed of vascinol and $20 \%$ vasicine inhibited ovalbumin-induced allergic reactions by about $37 \%$ at a concentration of $5 \mathrm{mg}{ }^{[17]}$. Potent antiallergic effects of vasicinone have been established in experiments conducted on mice, rats and guinea pigs ${ }^{[18]}$.

Anti-tubercular activity: Adhatoda alkaloid vasicine, produces chemical constituents bromhexine and ambroxol, two widely used mucolytics. Growth inhibitory effects on Mycobacterium tuberculosis of these chemicals have been established. Adusa also has indirect effects on tuberculosis by increasing lysozyme and rifampicin levels in bronchial 
secretions, lung tissue and sputum; which indicates that it may be used as adjuvant in the treatment of tuberculosis ${ }^{[19}$, 20]

Abortifacient and uterotonic activity: Adhatoda vasica has been used for inducing abortion and for stimulating uterine contractions in order to speed childbirth because of its abortifacient and uterotonic properties respectively ${ }^{[1]}$. Significant uterotonic activity of the alkaloid vasicine has been demonstrated through studies on human subjects. This pharmacological action appears to be induced by the presence or absence of certain estrogens. In a research, human myometrial strips taken from the uterus of both pregnant and non-pregnant women were treated with Adhatoda to study activity of vasicine in stimulating uterine contractions. The herb was found to induce uterine contractions, with effectiveness similar to the drug oxytocin [21]. Anti-reproductive properties of Adhatoda vasica were also anecdotally confirmed by local women during the research period ${ }^{[22]}$. Abortifacient properties of Adhatoda were also demonstrated through animal studies. In a study, aqueous or $90 \%$ ethanol plant extract was orally given to rats and guinea pigs for 10 days after insemination. It was found that extract of leaf of Adhatoda vasica at doses equivalent to $175 \mathrm{mg} / \mathrm{kg}$ was $100 \%$ abortive [23]. Abortifacient effect of Adhatoda vasica was also shown in guinea pigs, with varied effectiveness according to the stage of pregnancy. More pronounced results were found when estrogens were used as a priming influence; this indicates that the action of vasicine was probably mediated via release of prostaglandins ${ }^{[24]}$.

Insecticidal activity: Use of adusa as an insecticide has been prevalent for centuries in India. Its leaves have been shown to control insect pests both in laboratory and warehouse conditions ${ }^{[25]}$. Many research have showed antifertility activity against several insect species, may due to its action on blocking the oviduct. Research has also proven Adhatoda's effectiveness as an insect repellent ${ }^{[26]}$.

Anti-bacterial activity: A leaf extract was investigated for antibacterial activity using the paper disc and dilution methods. In vitro studies on Adhatoda's alkaloids showed a strong activity against the bacteria Pseudomonas aeruginosa. It was also noted that it possesses significant antibacterial activity against the gram-positive bacteria strains like Streptococcus faecalis, Staphylococcus aureus, Staphylococcus Epidermidis and against the gram-negative bacteria like Escherichia coli ${ }^{[27]}$.

\section{Conclusion}

Athatoda vasica has many biological activities that have been proved by many experimental studies. It represents a class of herbal medicine that has very strong conceptual or traditional base and a strong experimental base for its use. Main alkaloid present in the leaves of the plant is vasicine, which causes small but persistent bronchodilatation. It also contains an essential oil which is mainly responsible for the expectorant action of the plant. Other alkaloids like vasicinone, vasicinolone and vasicol are also present in the leaves and roots; they contribute to the bronchodilatory effect of the plant through anticholinergic action on the vagal innervation of the bronchi. The plant has great potential in treating various disorders but there is still scope and need to further conduct clinical trials to prove its clinical efficacy.

\section{References}

1. Claeson UP, Malmfors T, Wikman G, Bruhn JG. Adhatoda vasica: A critical review of ethnopharmacological and toxicological data. J Ethnopharma 2000; 72:1-20.

2. Anonymous. The Unani Pharmacopeia of India. VolVI, Part-1, New Delhi: CCRUM, Ministry Health and Family Welfare. Govt. of India, 2009, 13-14.

3. Shinwari ZK, Shah M. The Ethnobotany of Khaghan district, Balochistan, Pakistan. Proc Sym Med Pl 1996; 12:35-38.

4. Pandita K, Bhatia MS, Thappa RK, Agarwal SG, Dhar KL, Atal CK et al. Seasonal variation of alkaloids of Adhatoda vasica and detection of glycosides and Noxides of vasicine and vasicinone. Planta Med 1983; 48:81-82.

5. Kabir H. Introduction to Ilmul-Advia. $1^{\text {st }}$ ed. Aligarh: Shamsher Publisher and Distributors, 2002, 123.

6. Shrivastava N, Shrivastava A, Banerjee A, Nivsakar M. Anti-ulcer activity of Adhatoda vasica Nees. J Herb Pharmacother 2006; 6(2):43-49.

7. Maikhuri RK, Gangwar AK. Ethnobiological notes on the Khasi and Garo tribes of Meghalaya, Northeast India. Econ Bot 1993; 47(4):345.

8. Dhar KL, Jain MP, Koul SK, Atal CK. Vasicol, a new alkaloid from Adhatoda vasica. Phytochem 1981; 20(2):319-21.

9. Jain MP, Sharma VK. Phytochemical investigation of roots of Adhatoda vasica. Planta Med 1982; 46:250. Doi: 10.1055/s-2007-971226.

10. Bhalla HL, Nimbkar AY. Preformulation studies III. Vasicinone, a bronchodilatory alkaloid from Adhatoda vasica Nees (absorption, potency and toxicity studies). Drug Dev Indian Pharm 1982; 8(6):833. Doi:10.3109/03639048209022128.

11. Dorsch W, Wagner H. New antiasthmatic drugs from traditional medicine. Int Arch Allergy Appl Immunol 1991; 94(1-4):262-65.

12. Dhuley JN. Antitussive effect of Adhatoda vasica extract on mechanical or chemical stimulation-induced coughing in animals. J Ethnopharm 1999; 67(3):361-65.

13. Lahiri PK, Pradhan SN. Pharmacological investigation of vasicinol, an alkaloid from Adhatoda vasica Nees. Indian J Exp Biol 1964; 2:219.

14. Bhargava MK, Singh H, Kumar A. Evaluation of Adhatoda vasica as a wound healing agent in buffaloes. Clinical, mechanical and biochemical studies. Indian Vet J 1988; 65(1):33-38.

15. Chaturvedi GN, Rai NP, Dhani R, Tiwari SK. Clinical trial of Adhatoda vasica syrup (vasa) in the patients of non-ulcer dyspepsia (Amlapitta). Anc Sci Life 1983; 3(1):19-23.

16. Rabinovich MI, Leskov AI, Gladkikh AS. Cholegogic properties of peganine. Vrachei, 1966, 181.

17. Paliwa JK, Dwivedi AD, Sihgh S, Gupta RC. Pharmacokinetics and in-situ absorption studies of a new anti-allergic compound 73/602 in rats. Int $\mathrm{J}$ Pharm 2000; 197(1-2):213-20.

18. Wagner H. Search for new plant constituents with potential antiphlogistic and antiallergic activity. Planta Med 1989; 55(3):235-41. 
19. Narimaian M, Badalyan M, Panosyan V, Gabrielyan E, Panossian A, Wikman $G$ et al. Randomized trial of a fixed combination (KanJang) of herbal extracts containing Adhatoda vasica, Echinacea purpurea and Eleutherococcus senticosus in patients with upper respiratory tract infections. Phytomed 2005; 12(8):53947.

20. Grange JM, Snell NJC. Activity of bromhexine and ambroxol, semi-synthetic derivatives of vasicine from the Indian shrub Adhatoda vasica, against Mycobacterium tuberculosis in vitro. $\mathrm{J}$ Ethnopharm 1996; 50(1):49-53.

21. Pahwa GS, Zutshi U, Atal CK. Chronic toxicity studies with vasicine from Adhatoda vasica Nees. in rats and monkeys. Indian J Exp Biol 1987; 25(7):467-70.

22. Gupta OP, Anand KK, Ghatak BJ, Ray, Atal CK. Vasicine, alkaloid of Adhatoda vasica, a promising uterotonicabortifacient. Indian J Exp Biol 1978; 16(10):1075-77.

23. Atal CK. The chemistry and pharmacology of vasicine, anew oxytocic and abortifacient. Jammu-Tawi: CSIR, Regional Research Laboratory, 1980.

24. Nath D, Sethi N, Singh RK, Jain AK. Commonly usedIndian abortifacient plants with special reference to their teratologic effects in rats. J Ethnopharm 1992; 36(2):147-54.

25. Srivastava AS, Saxena HP, Singh DR. Adhatoda vasica, a promising insecticide against pests of storage. Lab Dev 1965; 3(2):138.

26. Saxena BP, Tikku K, Atal CK. Insect antifertility and antifeedant alleochemics in Adhatoda vasica. Insect Sci Appl 1986; 7(4):489-93.

27. Patel VK, Venkatakrishna BH. In vitro study of antimicrobial activity of Adhatoda vasica Linn. (Leaf extract) on gingival inflammation a preliminary report. Indian J Med Sci 1984; 38(4):70-72. 